April 2003 - NREL/CP-520-33940

\title{
Analysis of the ZnTe:Cu Contact on CdS/CdTe Solar Cells
}

\section{Preprint}

\author{
T.A. Gessert, M.J. Romero, R.G. Dhere, and S.E. Asher
}

To be presented at the 2003 Materials Research Society Spring Meeting

San Francisco, California

April 21-25, 2003

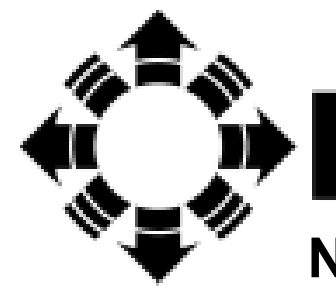

National Renewable Energy Laboratory

1617 Cole Boulevard

Golden, Colorado 80401-3393

NREL is a U.S. Department of Energy Laboratory

Operated by Midwest Research Institute $\bullet$ Battelle $\bullet$ Bechtel

Contract No. DE-AC36-99-G010337 


\section{NOTICE}

The submitted manuscript has been offered by an employee of the Midwest Research Institute (MRI), a contractor of the US Government under Contract No. DE-AC36-99G010337. Accordingly, the US Government and MRI retain a nonexclusive royalty-free license to publish or reproduce the published form of this contribution, or allow others to do so, for US Government purposes.

This report was prepared as an account of work sponsored by an agency of the United States government. Neither the United States government nor any agency thereof, nor any of their employees, makes any warranty, express or implied, or assumes any legal liability or responsibility for the accuracy, completeness, or usefulness of any information, apparatus, product, or process disclosed, or represents that its use would not infringe privately owned rights. Reference herein to any specific commercial product, process, or service by trade name, trademark, manufacturer, or otherwise does not necessarily constitute or imply its endorsement, recommendation, or favoring by the United States government or any agency thereof. The views and opinions of authors expressed herein do not necessarily state or reflect those of the United States government or any agency thereof.

Available electronically at http://www.osti.gov/bridge

Available for a processing fee to U.S. Department of Energy and its contractors, in paper, from:

U.S. Department of Energy

Office of Scientific and Technical Information

P.O. Box 62

Oak Ridge, TN 37831-0062

phone: 865.576.8401

fax: 865.576.5728

email: reports@adonis.osti.gov

Available for sale to the public, in paper, from:

U.S. Department of Commerce

National Technical Information Service

5285 Port Royal Road

Springfield, VA 22161

phone: 800.553 .6847

fax: 703.605.6900

email: orders@ntis.fedworld.gov

online ordering: http://www.ntis.gov/ordering.htm

Printed on paper containing at least $50 \%$ wastepaper, including $20 \%$ postconsumer waste 


\title{
Analysis of the ZnTe:Cu Contact on CdS/CdTe Solar Cells
}

\author{
T.A. Gessert, M.J. Romero, R.G. Dhere, and S.E. Asher \\ National Renewable Energy Laboratory (NREL), Golden, CO 80401, U.S.A.
}

\begin{abstract}
We report on the recent use of cathodoluminescence (CL) to probe the depth-dependent changes in radiative recombination that occur in $\mathrm{CdTe}$ devices during $\mathrm{ZnTe}$ : $\mathrm{Cu}$ contacting procedures. These types of CL measurements may be useful to assist in linking impurity diffusion (e.g., $\mathrm{Cu}$ ) from the contact with depth-dependent variation in electrical activation within the CdTe layer. Variable-energy CL suggests that diffusion from the ZnTe:Cu contact interface may assist in reducing effects of shallow donors in the CdTe bulk, and yield higher acceptor levels in the region near the contact. CL analysis near abrupt metal discontinuities provides estimates of diffusion lengths for carriers associated with both excitonic and donor-toacceptor pair recombination. Finally, CL measurements at increasing excitation levels (i.e., increasing electron-beam current) provides estimates of the defect state density, as well as providing evidence that discrete multiple defect bands may exist in CdTe prior to contacting.
\end{abstract}

\section{INTRODUCTION}

The demonstration of a manufacturable, stable, low-resistance, ohmic contact for p-CdTe polycrystalline photovoltaic devices remains an important goal of the CdTe research community. Devices with fill factors approaching $77 \%$ have been demonstrated by incorporating a $\mathrm{Cu}$-doped ZnTe contact interface layer between the CdTe absorber and a Ti metallization [1]. This contacting process uses vacuum processing, including ion-beam milling instead of wet-chemical etching, to fabricate the contact. In addition to potential manufacturing advantages, the high degree of control afforded by the vacuum processes used for this contact can enable systematic variation of critical aspects of the contact design. These types of studies suggest that the contacting processes used in typical $\mathrm{CdS} / \mathrm{CdTe}$ have a much greater role in device performance than simply providing a low-resistance pathway for current transport. Previous work has shown that various impurities enter the CdTe absorber layer during both the $\mathrm{CdCl}_{2}$ and the contacting processes. Of these impurities, $\mathrm{Cu}$ is believed to be a very important component of ultimate device performance, and significant effort has been directed toward understanding effects of $\mathrm{Cu}$ in the device following various process steps and/or accelerated life testing procedures $[2,3,4]$.

Understanding how contact processes lead to particular depth-dependent $\mathrm{Cu}$ concentrations is critical to designing processes that produce reproducible device performance. However, understanding how this baseline device operation in achieved, and identifying methods to significantly improve performance requires that the depth-dependence of the electrical activation of $\mathrm{Cu}$ in the $\mathrm{CdS} / \mathrm{CdTe}$ device also be understood. Appropriate techniques in this type of study would not only correlate $\mathrm{Cu}$ concentration with electrical properties, but provide insight into the particular defect(s) that produce these properties. Because the formation of $\mathrm{Cu}$-related defects would be expected to affect recombination processes, our recent efforts toward analyzing the depth-dependence of $\mathrm{Cu}$ activation have involved examination of the depth-dependent radiative recombination using CL. This analysis indicates that significant modification of the radiative recombination spectra occurs during contacting and suggests that understanding both the 
diffusion profiles and depth-dependant recombination may yield insight into device evolution and stability.

\section{EXPERIMENTAL DETAILS}

$\mathrm{CdS} / \mathrm{CdTe}$ materials used in this investigation were produced by both First Solar and NREL. The CdS and CdTe layers of the First Solar material were deposited by close-spaced sublimation (CSS) at $\sim 580^{\circ} \mathrm{C}$ onto 5-mm-thick soda-lime glass to nominal thicknesses of $\sim 300 \mathrm{~nm}$ and $\sim 4.5$ $\mu \mathrm{m}$, respectively. This was followed by a wet $\mathrm{CdCl}_{2}$ treatment at First Solar. Previous development of the NREL ZnTe:Cu/Ti contact on this type material has produced devices with open-circuit voltage $\left(\mathrm{V}_{\text {oc }}\right)$ of $\sim 820 \mathrm{mV}$, fill factors of $77 \%$, and device efficiency of $\sim 10 \%-11 \%$ (performance of these devices is limited primarily by low current density due to thick CdS) [1]. The NREL CdS/CdTe device material used 1-mm-thick 7059 glass substrates, a 450-nm $\mathrm{SnO}_{2}: \mathrm{F} / \mathrm{SnO}_{2}$ bilayer formed by chemical-vapor deposition (CVD) of tetramethyltin and oxygen, $\sim 100$-nm-thick CdS formed by chemical-bath deposition, an 8- $\mu \mathrm{m}$-thick CdTe layer formed by CSS, and a vapor $\mathrm{CdCl}_{2}$ treatment [5]. Representative efficiencies for these particular NREL devices (processed with a $\mathrm{Cu}$-doped graphite-paste contact) were $11 \%-12 \%$.

The $\mathrm{ZnTe}: \mathrm{Cu} / \mathrm{Ti}$ back contact was produced using a sequential process involving 2-h temperature equilibration at $\sim 350^{\circ} \mathrm{C}$, ion-beam milling the CdTe surface to a depth of $\sim 100 \mathrm{~nm}$, r.f.-sputter deposition of $\sim 0.5 \mu \mathrm{m}$ of $\mathrm{ZnTe}: \mathrm{Cu}(\sim 6$ at. $\% \mathrm{Cu})$, and $0.5 \mu \mathrm{m}$ of d.c.-sputter-deposited $\mathrm{Ti}$ (as the sample cooled from $\sim 300^{\circ}$ to $100^{\circ} \mathrm{C}$ ).

CL measurements were performed in a JEOL 5800 scanning electron microscope at various electron-beam energies and beam currents. CL spectra were acquired with a Princeton LN/CCD1340/400 cryogenic charge-coupled device. Wavelength-dispersive images were reconstructed from the CL spectra by synchronizing spectra acquisition with the electron-beam positioning system. Secondary-ion mass spectroscopy (SIMS) was performed from the contacted side of the devices using a Cameca IMS-5F instrument tuned for a mass resolution $(\mathrm{M} / \Delta \mathrm{M})$ of $\sim 4000$ to allow for separation of $\mathrm{Cu}$ from the Te and $\mathrm{S}$ species.

\section{DISCUSSION}

Figure 1 shows representative SIMS analysis of the NREL ZnTe:Cu/Ti contact, as well as comparisons with contacts produced on the same $\mathrm{CdS} / \mathrm{CdTe}$ material using $\mathrm{Cu}$ doped graphite-paste produced by NREL and the University of South Florida (USF). These quantified depth profiles show that the various contacting processes produce similar $\mathrm{Cu}$ concentration profiles. The figure also shows that a significant amount of the $\mathrm{Cu}$ enters the CdTe layer during the $\mathrm{CdCl}_{2}$ treatment. It is also noteworthy that the $\mathrm{ZnTe}: \mathrm{Cu}$ contact produces a lower concentration $\mathrm{Cu}$ in the $\mathrm{CdS}$ layer, even though it experiences a higher processing

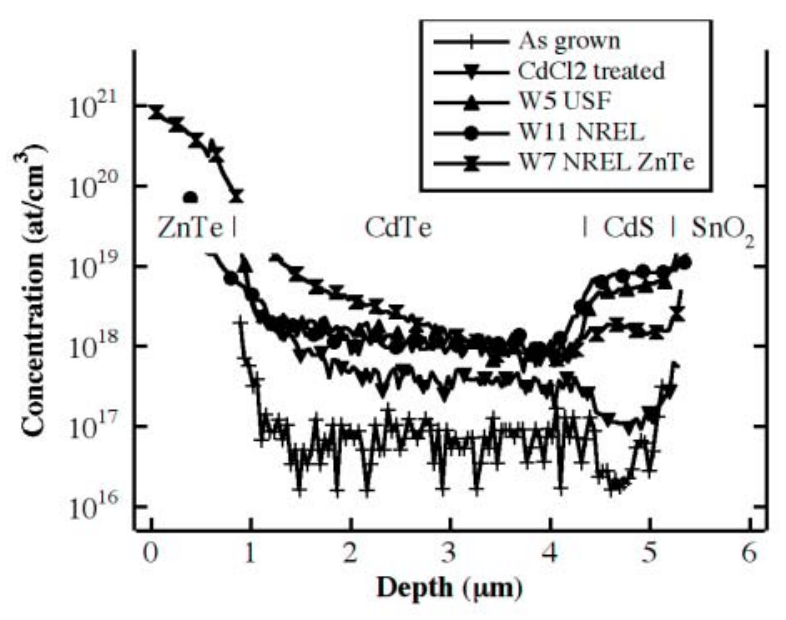

Figure 1. SIMS analysis of $\mathrm{Cu}$ levels in First Solar vaportransport deposited material that was wet- $\mathrm{CdCl}_{2}$ treated and contacted with the USF C/Cu paste (USF), the NREL C/Cu paste (NREL), and the NREL ZnTe:Cu/Ti (NREL ZnTe). 
temperature than the paste contacts $\left(\sim 350^{\circ} \mathrm{C}\right.$ vs. $\left.\sim 200^{\circ} \mathrm{C}\right)$. Potential effects of these differences on device performance and/or stability have not been correlated. However, because both the performance and $\mathrm{Cu}$ concentration profiles of these devices are similar, it seems likely that improved understanding of the role of $\mathrm{Cu}$ in any of these contact may provide significant insight into the function of other typical contacts.

Figure 2 shows the configuration used for $\mathrm{CL}$ analysis. One of the methods available to analyze the near-contact region is to vary the energy of the electron beam. As indicated in Table 1, this method can be used to probe radiative recombination from $\sim 0.1$ to $\sim 3 \mu \mathrm{m}$ from the contacted surface. In the example shown in Fig. 3, the beam is incident through either a $\sim 50 \mathrm{~nm}$ or $\sim 200 \mathrm{~nm} \mathrm{ZnTe}: \mathrm{Cu}$ contact interface that has been deposited onto a $\mathrm{CdS} / \mathrm{CdTe}$ device following ion-beam milling. The CL spectra show two primary luminescence peaks: a high-energy peak at $\sim 1.5-1.6 \mathrm{eV}$, and a broader peak centered at $\sim 1.4 \mathrm{eV}$. The higherenergy peak is ascribed to excitonic and shallow-donor transitions, whereas the broad peak at $\sim 1.4 \mathrm{eV}$ is believed to be related to donor-to-acceptor (DAP) transitions and related phonon replicas. The acceptor states of the DAP transitions are believed to correspond to cadmium vacancy $\left(\mathrm{V}_{\mathrm{Cd}}\right)$ complexes, such as the A center [6,7]. Analysis of the exciton

Table 1. Maximum range of penetration for primarybeam electrons and density of states associated with DAP radiative recombination.

\begin{tabular}{|l|l|l|l|l|}
\hline $\mathrm{E}_{\mathrm{b}}(\mathrm{keV})$ & 5 & 10 & 20 & 30 \\
\hline $\mathrm{R}_{\mathrm{e}}(\mu \mathrm{m})$ & 0.12 & 0.41 & 1.39 & 2.83 \\
\hline $\begin{array}{l}* \text { DAP } \\
\text { Density }\left(\mathrm{cm}^{-3}\right)\end{array}$ & $2 \times 10^{11}$ & $2 \times 10^{12}$ & $3 \times 10^{13}$ & $8 \times 10^{13}$ \\
\hline $\begin{array}{l}\text { DAP } \\
\text { Density }\left(\mathrm{cm}^{-3}\right)\end{array}$ & - & $6 \times 10^{10}$ & $5 \times 10^{11}$ & $8 \times 10^{12}$ \\
\hline
\end{tabular}

*Before $\mathrm{ZnTe}: \mathrm{Cu}$ contact

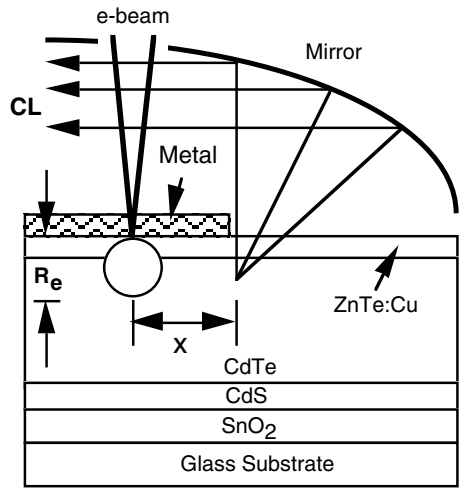

Figure 2. Schematic diagram illustrating the analysis configuration used for CL analysis. transition in Fig. 3 shows that it is attenuated by the presence of the $\mathrm{ZnTe}: \mathrm{Cu}$ layer. Deeper penetration through the thinner $\mathrm{ZnTe}$ :Cu layers (i.e., 20-keV beam, 50-nm ZnTe:Cu) produces a more intense CL signal and a substantial shift in the exciton peak. It has been suggested that the shift may be due to the probed CdTe region containing more shallow donor states than the region nearer the contact interface. If this is true, it may suggest that the uncontacted CdTe is less ptype than often assumed, and that sufficient $\mathrm{Cu}$ diffusion from the contact is required to effect not only higher acceptor level near the contact, but also produce CdTe bulk material with higher acceptor levels [3]. In contrast to the exciton peak, the position of the DAP emission remains relatively unchanged by increasing $\mathrm{ZnTe}: \mathrm{Cu}$ thickness and its intensity increases with increasing penetration depth. Similar CL analysis at low energy $(10 \mathrm{keV})$ suggests that the $\mathrm{Cu}$ diffusion from the $\mathrm{ZnTe}: \mathrm{Cu}$ (as observed by SIMS analysis above)

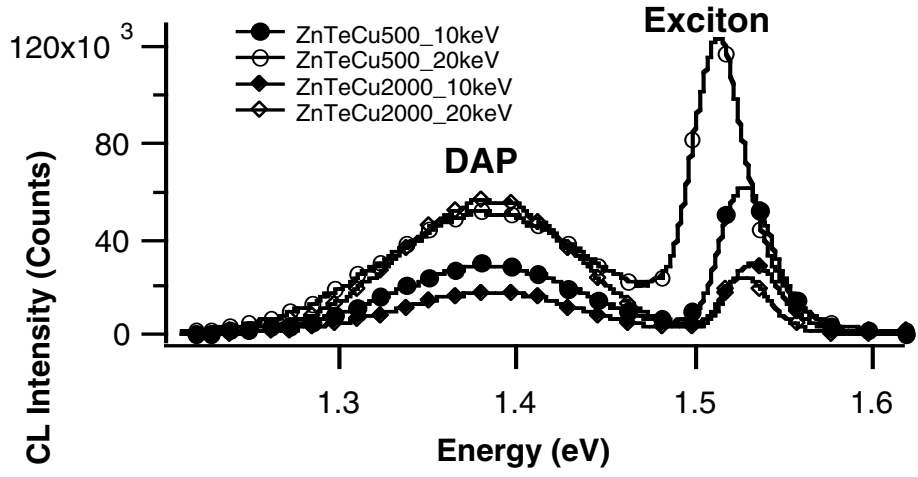

Figure 3. Variable-energy CL spectra $(10 \mathrm{eV}$ or $20 \mathrm{eV})$ of CdTe back surface following ZnTe:Cu/Ti deposition (500 $\AA$ or $2000 \AA$ ) with Ti layer removed. Temperature $=77 \mathrm{~K}$. 
produces emission consistent with the formation of $\mathrm{Cu}_{\mathrm{Cd}}$ defects [8] whereas higher energy analysis (30 keV) shows that the DAP complex remains active deeper in the CdTe [9]. These DAP results also suggest that electrical activation of $\mathrm{Cu}$, and thus the electrical properties of the $\mathrm{CdTe}$, change significantly as a function of distance from the $\mathrm{ZnTe}: \mathrm{Cu} / \mathrm{CdTe}$ interface.

Another CL analysis technique useful for contact studies is based on the fact that, although an electron beam can penetrate a thin metal pad, this same metallization will reflect optical luminescence generated directly beneath it. However, if the lifetime of the minority carriers is sufficient long, some recombination may occur outside of the metal pad, and a CL signal can be detected. Figure 2 indicates the configuration used for this type of analysis. In this figure, as the electron beam is scanned from right to left, the beam will encounter the edge of the metal pad. Once this occurs, only the radiative recombination of carriers with diffusion length longer than the distance to the metal edge (x) will be observed. Analysis of the CL intensity as a function of $\mathrm{x}$ can provide separate estimates of the diffusion length for exciton and DAP-related diffusion $\left(\mathrm{L}_{\mathrm{x}}\right.$ and $\mathrm{L}_{\mathrm{DAP}}$, respectively) [7]. Successful application of this technique requires that an abrupt metal edge can be formed, and that any surface layers (i.e., contact interface layers) remaining outside of the metallization are transparent to the luminescence.

Because the bandgap of the $\mathrm{ZnTe}: \mathrm{Cu}$ layer is $\sim 2.25 \mathrm{eV}$, and because photolithographic techniques and selective etches are used to pattern the contacts, we plan to use this technique to probe this contact. In contrast, the Cu-doped paste contact used for NREL "baseline devices" incorporates a chemical etch (nitric acid + phosphoric acid) to form a thick Te layer prior to $\mathrm{Cu}$ doped paste application. In this case, the Te layer is optically dense to the luminescence, and thus, a CL signal cannot be acquired. Nevertheless, the technique has been used to provide baseline information on the NREL CdTe device material prior to contacting. In this case (data shown in Fig. 4), a $2 \times 2$ pattern of $500-\mu \mathrm{m} \mathrm{x}$ $500-\mu \mathrm{m}$ pads was formed using a 25 50-nm thick Al layer deposited through a shadow mask at room temperature. Although we have not yet explored if possible Al diffusion affects the analysis, (because of the low-temperature of the deposition process) we assume diffusion is minimal and the Al pad functions only as a CL reflector.

Figure 4 shows that the exciton peak of the CL spectrum attenuates quickly as the beam proceeds into the metallization. In contrast, the relative contribution of the 1.4-eV peak decreases much more slowly. Taken together, these results suggest a

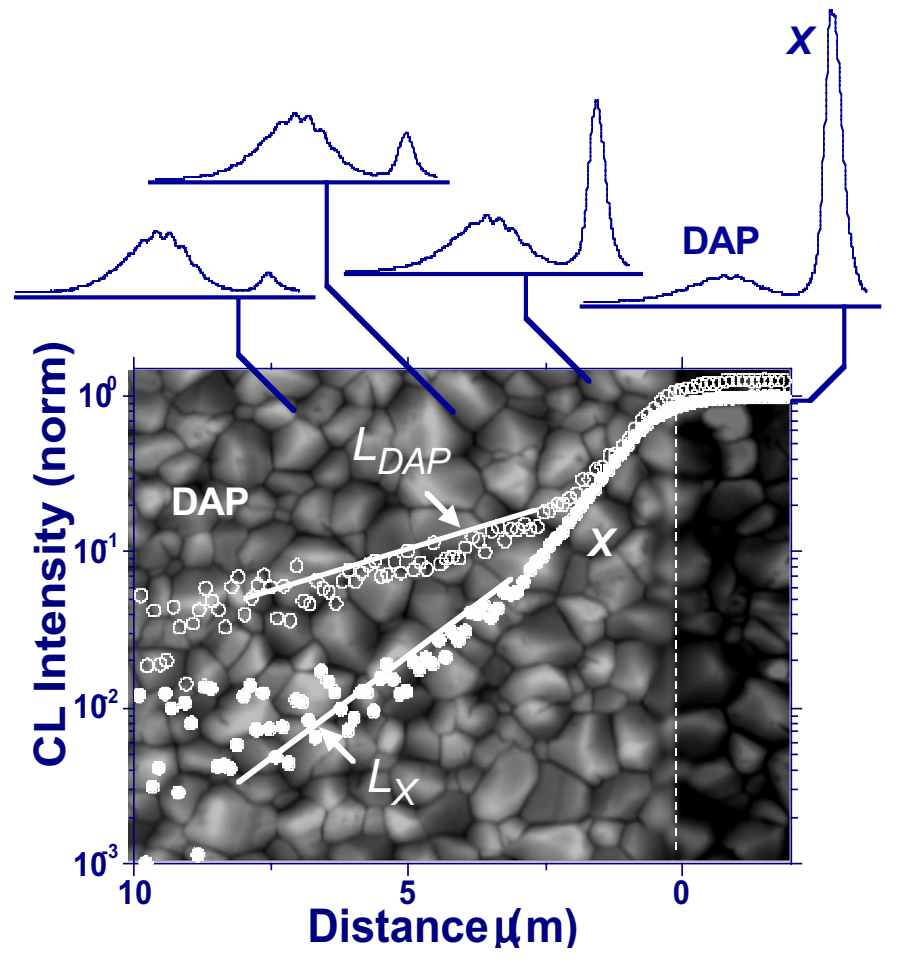

Figure 4. Secondary-electron image of a Al metallized NRELdeposited CdTe film (left side) and spectra acquired for the different locations. The relative contribution of the DAP transitions to the exciton emission $(\mathrm{X})$ increases drastically over the distance from the edge of the pattern, suggesting a longer diffusion length for the DAP recombination $\left(\mathrm{L}_{\mathrm{DAP}}\right)$ compared with the exciton diffusion length $\left(\mathrm{L}_{\mathrm{X}}\right)$. 
longer diffusion length for carriers that recombine through the DAP-related emission relative to diffusion length of carriers recombine via excitons. Indeed, straight-line fits of the appropriate portion of these data in Fig. 4 indicated $\mathrm{L}_{X}$ and $\mathrm{L}_{\text {DAP }}$ of $1.5 \mu \mathrm{m}$ and $5.5 \mu \mathrm{m}$, respectively [7].

Another method used to explore recombination processes near the contact region is to monitor the CL spectra as a function of electron-beam current (i.e., excitation intensity). As the number of beam-generated carriers increases, the relative intensities of the exciton and DAP evolve. Although the number of excitonic states available is unlimited, the DAP-related recombination is limited by the availability of these defects. Saturation of the DAP transition occurs when the density of carriers generated by the electron beam is comparable to the density of defect complexes involved in a particular transition [10].

Figure 5a shows CL emission spectra of a $\mathrm{CdCl}_{2}$-treated CdTe film prior to contacting for four selected beam intensities (as defined relative to the S1 and S2 markers in Fig. 5b). These spectra have been normalized to illustrate how the DAP emission shifts to higher energies as the excitation level increases. An alternative method to illustrate this effect is shown by comparing Figs. 5b and 5c. Figure 5b shows the same analysis as in Fig. 5a, but with the luminescent intensity mapped against the log of the beam current. Figure $5 \mathrm{c}$ shows a sample that is nominally identical to that used in Figs. 5 a and 5 b, but after contacting with a $0.5-\mu m$-thick $\mathrm{ZnTe}: \mathrm{Cu}$ layer. Figure $5 \mathrm{c}$ reveals that the DAP shift to higher energy is not observed in the contacted sample. Estimates of the DAP state density from these CL spectra (combined with diffusion length on these samples performed similar to Fig. 4) are provided in Table 1 [7,11].

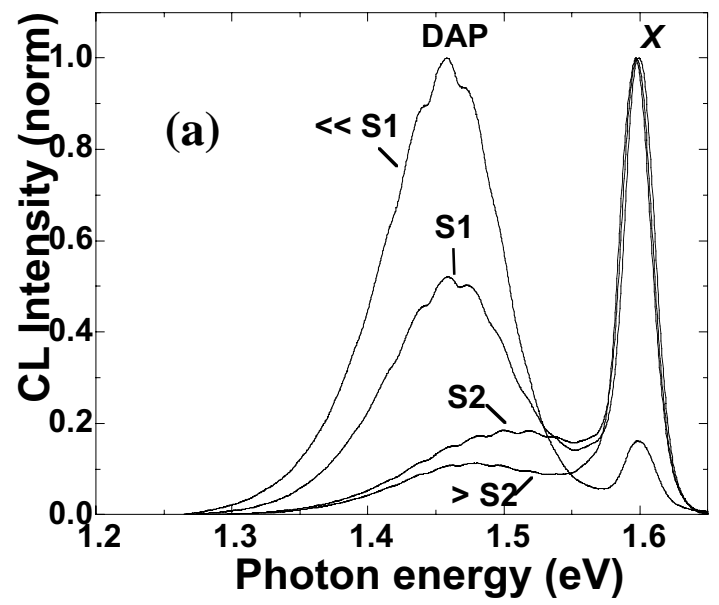

Figure 5. (a) Normalized CL spectra of non-contacted CdTe illustrating shift of DAP emission with increasing beam current at various levels shown in (b). (b-c) Effect of electron-beam current on emission spectrum (b) prior to and (c) after contacting.

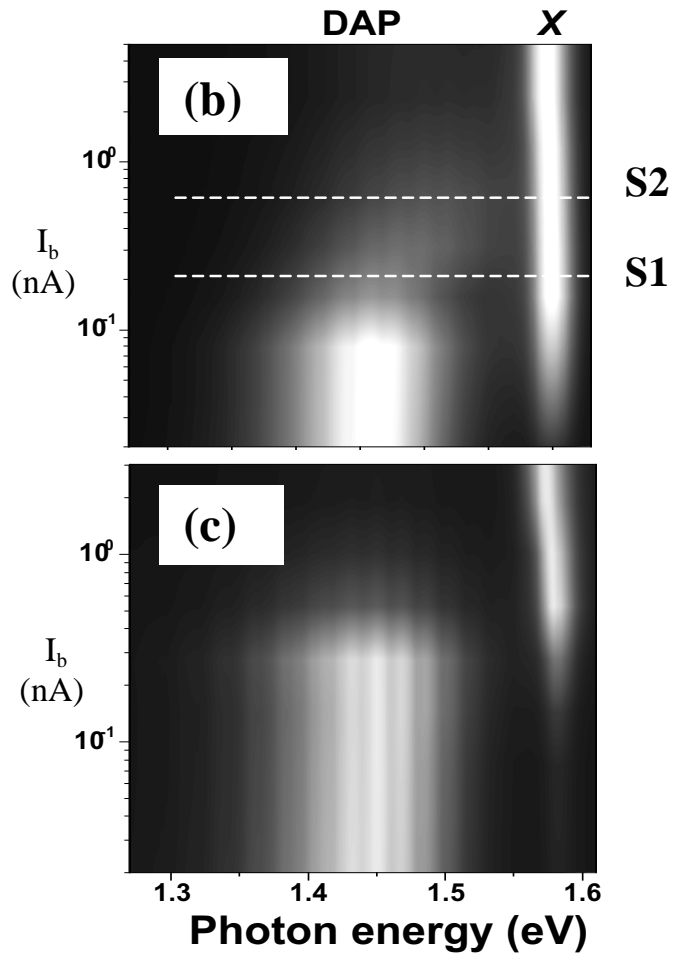

S2

The spectral shift in the DAP luminescence shown in Figs. 5a and 5b may be a manifestation of the existence of distinct bands of defect levels in the CdTe film prior to contacting. A schematic illustration of this possibility is shown in Fig. 6. (It is also noted that the existence of multiple discrete bands is not observed for similar analysis performed on polycrystalline CIGS [10]). Because this shift is not observed for the $\mathrm{ZnTe} \mathrm{Cu}$ contacted sample, we considered that it may 
be possible to probe depthdependent $\mathrm{Cu}$ activation by using $\mathrm{CL}$ at high beam current along CdTe cross-sections.

Unfortunately, as has been observed in other surface analysis techniques, CdTe samples are highly resistive unless $\mathrm{Cu}$ has been allowed to diffuse into the sample. Therefore, non-contacted CdTe samples experience significant charging at high beam currents, and this leads to significant problems in CL analysis.

\section{CONCLUSIONS}

Expanding our level of understanding of contact processes on the $\mathrm{CdS} / \mathrm{CdTe}$ device will require measurements that probe the extent of electrical activation of $\mathrm{Cu}$ in the various regions of CdTe. We have begun to use CL to assess the depth-dependant radiative recombination in the region near the back contact. These analyses have indicated that recombination processes differ significantly with depth into the CdTe. Variable-energy spectroscopic CL analysis provided baseline information related to how various steps of the contact process affect the radiative recombination as a function of depth. Variations on these techniques have also provided insight into the minority-carrier lifetime associated with particular recombination mechanisms. Finally, by varying the electron-beam current (i.e., excitation level), the density of DAP defect levels was estimated, and the possibility of multiple discrete bands of defect levels established.

\section{ACKNOWLEDGEMENTS}

The authors acknowledge First Solar LLC for samples and valuable technical discussion, Chitra Narayanswamy of NREL for providing the NREL Cu-paste contact, and Chris Ferekides of the University of South Florida for providing samples with the USF Cu-paste contact. This research was supported under DOE Contract No. DE-AC36-99GO10337.

\section{REFERENCES}

1. T.A. Gessert, A. Duda, S.E. Asher, C. Narayanswamy, and D. Rose, Proc. $28^{\text {th }}$ IEEE Photovoltaic Specialists Conf., Anchorage, Alaska, Sept. 15-22, 2000 (IEEE, Piscataway, NJ, USA) pp. 654-657.

2. S.E. Asher, et. al., Proc. $28^{\text {th }}$ IEEE Photovoltaic Specialists Conf., Anchorage, Alaska, Sept. 15-22, 2000 (IEEE, Piscataway, NJ, USA) pp. 479-482.

3. T.A. Gessert, M.J. Romero, S. Johnston, B. Keyes, and P. Dippo, Proc. $29^{\text {th }}$ IEEE PV Specialists Conf., New Orleans, LA, May 20-25, 2002 (IEEE, Piscataway, NJ, USA) pp. 535-538.

4. K.D. Dobson, I. Visoly-Fisher, G.Hodes, D. Cahen, Solar Energy Materials \& Solar Cells 62 295-325 (2000)

5. D. Rose, F. Hasoon, R. Dhere, D. Albin, R. Ribelin, X. Li, Y Mahathongdy, T. Gessert, and P. Sheldon, Prog. Photovolt: Res. Appl. 7, 3312-340 (1999).

6. $\quad$ D.M. Hofmann, P. Omling, and H.G. Grimmeiss, Phys. Rev. B, 45 (11) 1992 6247-6250.

7. $\quad$ M.J. Romero, T.A. Gessert, and M.M. Al-Jassim, Appl. Phys. Lett., 81, (17) 3161-3162 (2002).

8. $\quad$ D. Grecu, A.D. Compaan, D. Young, U. Jayamaha, and D.H. Rose, J. Appl. Phys. 88 (5) (2000) 2490-2496.

9. T.A. Gessert, M.J. Romero, and S. E. Asher, Proc. NREL NCPV Review Meeting, Lakewood, CO, Oct. 14-17, 2001, pp. 189-190.

10. M.J. Romero, W. Metzger, T.A. Gessert, D.A. Albin, and M.M. Al-Jassim, Proc. NREL NCPV Review Meeting, Denver, CO, March 24-26 (2003).

11. M.J. Romero, T.A. Gessert, M.M. Al-Jassim, R.G. Dhere, D.S. Albin, and H. R. Moutinho, Symposium F: Defect- and Impurity-Engineered Semiconductors and Devices III, Spring 2002 MRS Meeting. 


\section{REPORT DOCUMENTATION PAGE}

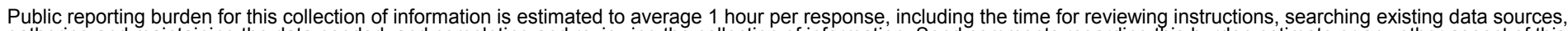

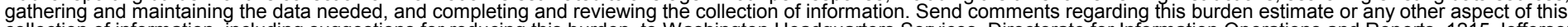
Davis Highway, Suite 1204, Arlington, VA 22202-4302, and to the Office of Management and Budget, Paperwork Reduction Project (0704-0188), Washington, DC 20503.
1. AGENCY USE ONLY (Leave blank)
2. REPORT DATE April 2003
3. REPORT TYPE AND DATES COVERED Conference paper

4. TITLE AND SUBTITLE

Analysis of the ZnTe:Cu Contact on CdS/CdTe Solar Cells: Preprint

5. FUNDING NUMBERS PVP34201

6. $\mathrm{AUTHOR}(\mathrm{S})$

T.A. Gessert, M.J. Romero, R.G. Dhere, and S.E. Asher

7. PERFORMING ORGANIZATION NAME(S) AND ADDRESS(ES)

National Renewable Energy Laboratory

1617 Cole Blvd.

REPORT NUMBER

NREL/CP-520-33940

Golden, CO 80401-3393

9. SPONSORING/MONITORING AGENCY NAME(S) AND ADDRESS(ES)

10. SPONSORING/MONITORING AGENCY REPORT NUMBER

11. SUPPLEMENTARY NOTES

12a. DISTRIBUTION/AVAILABILITY STATEMENT

National Technical Information Service

12b. DISTRIBUTION CODE

U.S. Department of Commerce

5285 Port Royal Road

Springfield, VA 22161

13. ABSTRACT (Maximum 200 words): We report on the recent use of cathodoluminescence $(C L)$ to probe the depth-dependent changes in radiative recombination that occur in CdTe devices during $\mathrm{ZnTe}: \mathrm{Cu}$ contacting procedures. These types of $\mathrm{CL}$ measurements may be useful to assist in linking impurity diffusion (e.g., Cu) from the contact with depth-dependent variation in electrical activation within the CdTe layer. Variable-energy CL suggests that diffusion from the $\mathrm{ZnTe:Cu}$ contact interface may assist in reducing donors levels in the CdTe bulk, and thereby yield p-type material in the region near the contact. CL analysis near abrupt metal discontinuities provides estimates of diffusion lengths for carriers associated with both excitonic and donor-to-acceptor pair recombination. Finally, CL measurements at increasing excitation levels (i.e., increasing electronbeam current) provides estimates of the defect state density, as well as providing evidence that discrete multiple defect bands may exist in CdTe prior to contacting.

14. SUBJECT TERMS: PV; cathodoluminescence (CL); CdTe; ZnTe:Cu contact; electronbeam current; depth-dependent; close-space sublimation; secondary-ion mass spectroscopy (SIMS);

15. NUMBER OF PAGES

16. PRICE CODE

17. SECURITY CLASSIFICATION OF REPORT Unclassified
18. SECURITY CLASSIFICATION OF THIS PAGE Unclassified
19. SECURITY CLASSIFICATION OF ABSTRACT Unclassified
20. LIMITATION OF ABSTRACT

UL 